\title{
A Laboratory-Scale Study of the Applicability of a Halophilic Sediment Bioelectrochemical System for in situ Reclamation of Water and Sediment in Brackish Aquaculture Ponds: Establishment, Bacterial Community and Performance Evaluation $\$$
}

\author{
Hai The Pham ${ }^{1 *}$, Hien Thi Tran ${ }^{1}$, Linh Thuy Vu ${ }^{1}$, Hien The Dang ${ }^{1}$, Thuy Thu Thi Nguyen ${ }^{1}$, Thu Ha Thi Dang ${ }^{1}$, \\ Mai Thanh Thi Nguyen ${ }^{3}$, Huy Quang Nguyen², and Byung Hong Kim ${ }^{4}$ \\ ${ }^{1}$ Research group for Physiology and Applications of Microorganisms (PHAM group), GREENLAB, Center for Life Science Research \\ (CELIFE) and Department of Microbiology - Faculty of Biology, Vietnam National University - University of Science, Hanoi 144, Vietnam \\ ${ }^{2}$ Department of Biochemistry and Molecular Biology, Faculty of Biology, Vietnam National University in Hanoi - University of Science, \\ Hanoi 144, Vietnam \\ ${ }^{3}$ Center for Experimental Biology, National Center for Technological Progress (NACENTECH), Hanoi, Vietnam \\ ${ }^{4}$ Korea Institute of Science and Technology, Seoul 02792, Republic of Korea
}

Received: May 20, 2019

Revised: June 16, 2019

Accepted: June 17, 2019

First published online

June 20, 2019

*Corresponding author

Phone: +84-943-318978

Fax: +84-24-38582069;

E-mail: phamthehai@vnu.edu.vn

S upplementary data for this http://jmb.or.kr.

pISSN 1017-7825, eISSN 1738-8872

Copyright (C) 2019 by

The Korean Society for Microbiology and Biotechnology paper are available on-line only at

In this study, we investigated the potential of using sediment bioelectrochemical systems (SBESs) for in situ treatment of the water and sediment in brackish aquaculture ponds polluted with uneaten feed. An SBES integrated into a laboratory-scale tank simulating a brackish aquaculture pond was established. This test tank and the control (not containing the SBES) were fed with shrimp feed in a scheme that mimics a situation where $50 \%$ of feed is uneaten. After the SBES was inoculated with microbial sources from actual shrimp pond sediments, electricity generation was well observed from the first experimental week, indicating successful enrichment of electrochemically active bacteria in the test tank sediment. The electricity generation became steady after 3 weeks of operation, with an average current density of $2.3 \mathrm{~mA} / \mathrm{m}^{2}$ anode surface and an average power density of $0.05 \mathrm{~mW} / \mathrm{m}^{2}$ anode surface. The SBES removed 20-30\% more COD of the tank water, compared to the control. After 1 year, the SBES also reduced the amount of sediment in the tank by $40 \%$ and thus could remove approximately $40 \%$ more COD and approximately 52\% more nitrogen from the sediment, compared to the control. Insignificant amounts of nitrite and nitrate were detected, suggesting complete removal of nitrogen by the system. PCR-DGGE-based analyses revealed the dominant presence of Methylophilus rhizosphaerae, Desulfatitalea tepidiphila and Thiothrix eikelboomii, which have not been found in bioelectrochemical systems before, in the bacterial community in the sediment of the SBES-containing tank. The results of this research demonstrate the potential application of SBESs in helping to reduce water pollution threats, fish and shrimp disease risks, and thus farmers' losses.

Keywords: Microbial fuel cell, sediment bioelectrochemical systems, brackish aquaculture, in situ bioremediation

\section{Introduction}

Over the last two decades, the aquaculture industry has been growing vigorously due to the increasing demand for aquaculture products. To satisfy this demand, the aquaculture farms have to increase their productivity by 
applying intensive rearing practices with huge daily feed loads. As a consequence, uneaten feed and waste produced by fish or shrimp result in a number of negative effects. The accumulation of these materials in a pond leads to increases in the amount of total nitrogen and organic matter in the water and the sediment of the pond [1]. Such a polluted pond is an ideal environment for microorganisms including pathogens to grow, causing increased chances of diseases to aquaculture animals. Diseases are the main threat to aquaculture productivity and can lead to heavy losses for farmers. For instance, in Vietnam, a potential aquaculture country, according to the National Agency of Aquaculture, the production of brackish water shrimp did not increase in 2012 due to widespread diseases [2]. Besides, effluent water from aquaculture ponds can be a serious source of contamination to receiving water bodies [3]. Therefore, in order to prevent disease outbreaks and to reduce farmers' losses as well as to protect the environment, it is essential and urgent to develop measures for the reduction of water pollution in aquaculture ponds.

There have been a number of studies on measures for the reduction of water pollution in aquaculture ponds. Since the 1980s, researchers have proposed to use artificial aeration systems to improve the removal of organic pollutants and nitrogen in intensive culture of marine fish and shrimp [3]. It has been reported that aeration can increase the aquaculture productivity but requires significant energy consumption (to propel the paddles) [3]. Another solution for the treatment of pond water is to design and construct separate systems to treat and recycle the water. Examples of these systems are integrated physicochemical and biological treatment plants, with biofilters, fluidized biological beds, rotating discs or constructed wetlands, etc. $[4,5]$. Although the treatment efficiencies of these separate systems are significantly high, they are not cost-effective because of constructional and operational costs and energy expenses for circulating water between the ponds and systems [1].

Recently, a number of studies have proposed the innovative idea of using bioelectrochemical systems as easy-to-operate solutions for the treatment of aquaculture effluent, particularly in removing nitrogen $[6,7]$. However, these systems are supposedly separate from the rearing ponds and thus still can not resolve the recirculation issue mentioned above. As a result of intensive studies on bioelectrochemical systems, the use of a sediment bioelectrochemical system (SBES) (or benthic bioelectrochemical system) has been shown to be an efficient solution for in situ reclamation of the water quality of freshwater aquaculture ponds $[1,8]$. In such a system, electrochemically active bacteria enriched at the sediment anode can oxidize organic matter in the sediment as well as in the water and harvest electrons before transferring them to the electrode [8-10]. Due to such unique properties, the SBES has indeed received a lot of research attention and can offer striking applications such as in situ sediment bioremediation, energy recovery from sediment or self-powered remote biomonitoring, etc. [11-17]. With the cathode floating on the water surface, the final electron acceptor of the system is actually oxygen from air diffused though the cathode. This enables the oxidation of organic substances to be driven by a high redox potential difference, without the need of transporting oxygen down to the sediment. With surface aeration usually applied in aquaculture ponds, oxygen supply for the cathode is even more abundant. On the other hand, with the maximum current of an SBES usually at $\mathrm{mA}$ levels [1, 18, 19], the cathode oxygen consumption is not significant enough to affect oxygen supply for reared animals.

Sajana and colleagues have constructed a laboratoryscale SBES and thoroughly investigated the efficiency of the system in treating the water of some aquaculture ponds [1]. Their research results showed that the experimented system could remove up to $80 \%$ COD (chemical oxygen demand) and more than $90 \%$ of total nitrogen in the water of the ponds where three typical kinds of Indian carp were reared [1]. Those results are inspiring and indicate a great potential of applying SBESs for in situ reclamation of the water quality of aquaculture ponds. Moreover, the operation of such an SBES is quite simple with low cost.

The SBES developed by Sajana and colleagues, though having a high treatment efficiency, has only been tested on freshwater aquaculture models [1]. There are, on the other hand, numerous aquaculture farms with brackish water all over the world. An aquaculture environment with high salinity is different from that with freshwater. Yet, in the authors' knowledge, there has been no reported study on the application of bioelectrochemical technologies for reclamation of the water quality of brackish aquaculture ponds. Therefore, in this research we established an SBES that is functional under brackish water conditions and investigated its efficiency in treating in situ the water and sediment of a laboratory-scale model of a brackish aquaculture pond. The bacterial consortium enriched at the sediment anode of the system was also analyzed in order to interpret its role in system performance. 


\section{Materials and Methods}

Design, Construction and Operation of a Brackish Aquaculture Pond Model with a Bioelectrochemical System Integratively Installed

Design and construction. Two rectangular, parallelepiped glass tanks, each having the dimensions of $30 \mathrm{~cm} \times 20 \mathrm{~cm} \times 25 \mathrm{~cm}$, were constructed (Fig. 1). In one tank (the test tank), a sediment bioelectrochemical system (SBES) was installed, while the other tank did not contain one and thus served as the control. The SBES installed in the test tank included an anode horizontally positioned at the bottom of the tank and a cathode on the water surface. The anode indeed consisted of a 2-cm-thick layer of graphite granules (3-5 $\mathrm{mm}$ in diameter) (Xilong Chemical Co., China) spreading all over the bottom of the tank and a graphite felt (Osaka Gas Chemicals Co., Japan) underlying the graphite granules. The graphite felt had the dimensions of $15 \mathrm{~cm} \times 7 \mathrm{~cm} \times$ $0.9 \mathrm{~cm}$. Another same-sized graphite felt was used as the cathode floating on the water surface, i.e. the cathode was in contact $50 \%$ with the water and 50\% with the air (to allow oxygen from air to diffuse in and accept electrons). To ensure that, the cathode graphite felt was fixed at a proper position and the tank water depth was also kept at a fixed level $(10 \mathrm{~cm}$ from the sediment, indicated by a bar on the glass) by a daily addition of distilled water to compensate for evaporation. Each graphite felt of the anode or the cathode was glued (with epoxy glue, Xilong Chemical Co.) to a graphite rod (5 $\mathrm{mm}$ in diameter) (Xilong Chemical Co.) to collect the electrical current. To prevent shortcircuiting, the part of the anode graphite rod immersed in water was tightly covered with an inert silicon tube. The graphite rods of the anode and the cathode were connected with copper wire to an external resistor of $10 \Omega$.

Each experimental tank was filled with pre-mixed artificial brackish water to a level that is $10 \mathrm{~cm}$ distant from the tank bottom, resulting in a final water volume of $6 \mathrm{~L}$. Thus the water body in the tank was just a $13^{3}$-fold miniature (with each dimension 13-fold miniaturized) of a $2.6 \mathrm{~m} \times 3.9 \mathrm{~m} \times 1.3 \mathrm{~m}$ water column of an average actual aquaculture pond, which usually has a depth of $1.3 \mathrm{~m}$ (Prof. Te Quang Bui, Research Institute of Aquaculture No. 1, personal communication) (Fig. 1). Artificial brackish water (15\% salinity) was created by diluting $101 \mathrm{~g}$ of Marinium Reef Sea Salt (Mariscience International Co. Ltd., Thailand) in 6 liters of tap water of each tank. According to the manufacturer's information, this salt mixture does not contain COD or nitrogen.

Operation. Both the test tank and control tank were fed with the shrimp feed GAMMA 6 (TOMBOY Co., Vietnam) at a rate of $0.051 \mathrm{~g} / \mathrm{d}$ per tank, equivalent to a COD loading rate of $8 \mathrm{mg} / \mathrm{l} / \mathrm{d}$ and a total nitrogen loading rate of $0.54 \mathrm{mg} / \mathrm{l} / \mathrm{d}$ (as the COD concentration and total nitrogen concentration of the feed were determined to be $941 \mathrm{mg} / \mathrm{g}$ and $63.6 \mathrm{mg} / \mathrm{g}$, respectively). This mimics the daily load of uneaten feed in an actual aquaculture pond with 30-day-old shrimp, based on the following calculation: The feeding rate usually applied for this type of shrimp in reality is approximately $22 \mathrm{~kg} / \mathrm{d}$ for $1,000 \mathrm{~m}^{2}$ pond area [20], which is equal to $22 \mathrm{~g} / \mathrm{d} / \mathrm{m}^{2}$. According to Prof. Te Quang Bui [20], from every $100 \mathrm{~kg}$ of feed supplied to a pond, up to $70 \mathrm{~kg}$ of waste can be produced from uneaten feed and excreted waste. In this study, we assumed a less serious situation in which only $50 \%$ of the feed was uneaten, then in a $2.6 \mathrm{~m} \times 3.9 \mathrm{~m} \times 1.3 \mathrm{~m}$ water column, the feeding rate should be $0.5 \times 22 \mathrm{~g} / \mathrm{d} / \mathrm{m}^{2} \times 2.6 \mathrm{~m} \times 3.9 \mathrm{~m}$. Thus in a $13^{3}$-fold miniature of that water column, which is the water body in our experimental tank, the feeding rate should be $1 /\left(13^{3}\right) \times 0.5$ $\times\left(22 \mathrm{~g} / \mathrm{d} / \mathrm{m}^{2} \times 2.6 \mathrm{~m} \times 3.9 \mathrm{~m}\right)$, resulting in the above-calculated feed load to our systems. In some experimental cases, the tanks were operated with a feeding rate of $0.11 \mathrm{~g} / \mathrm{d}$ per tank, i.e. the food supply was doubled ( $16 \mathrm{mg} / \mathrm{l}$ of COD per day and $1.08 \mathrm{mg} / \mathrm{l}$ of total nitrogen per day). This mimics the daily load of uneaten feed (also at a ratio of $50 \%$ ) in an actual aquaculture pond with 60day-old shrimp, based on a calculation similar to the one stated

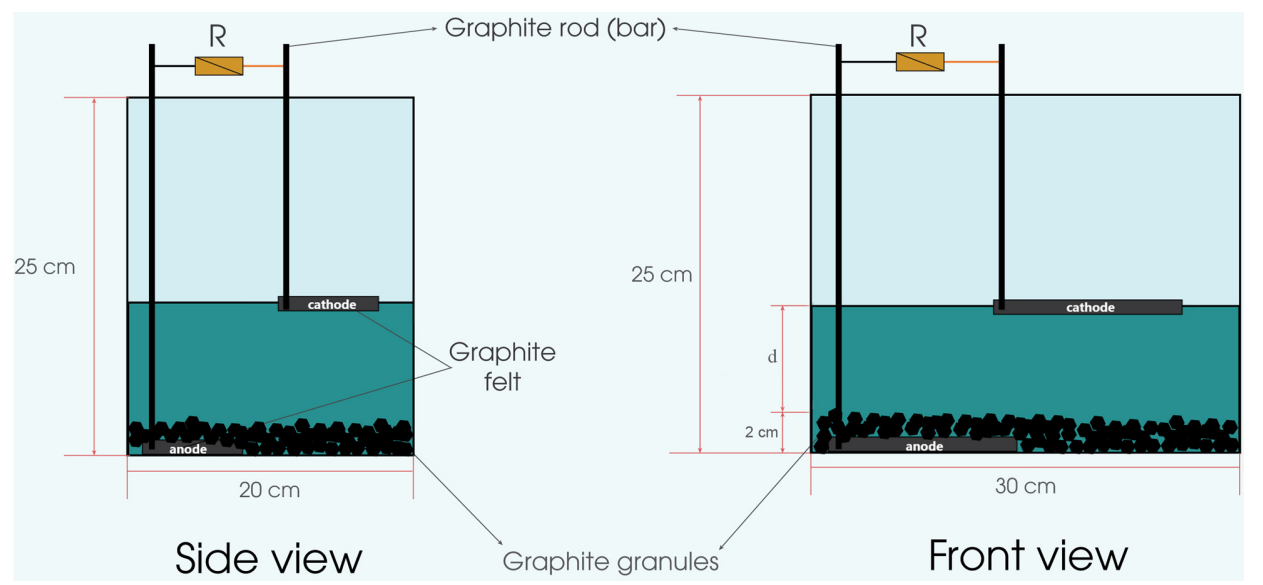

Fig. 1. Design of the aquaculture model tank installed with the sediment bioelectrochemical system used in the study. Note: R: resistance. The cover of the tank was made of glass. The distance $(\mathrm{d})$ between the electrodes was $10 \mathrm{~cm}$ by default. 
above. The systems were operated at room temperature $\left(27 \pm 3^{\circ} \mathrm{C}\right)$. In this laboratory-scale study, we only focus on mimicking the uneaten feed load, as this is considered the major organic contaminant source in aquaculture ponds [21, 22], thus assuming that fish or shrimp excreta are insignificant.

Measurement and calculation of electrical parameters. A realtime digital multimeter (Keithley model 2700, Keithley Instruments Inc., USA) was used to measure the voltage between the anode and the cathode of the SBES installed in the test tank. Electrical parameters (current $\mathrm{I}(\mathrm{A})$, voltage $\mathrm{U}(\mathrm{V})$, power $\mathrm{P}(\mathrm{W})$ and resistance $R(W)$ ) were measured and/or calculated according to Aelterman et al. (2006) [23] and Logan et al. (2006) [24]. Power density and current density were calculated with the total anode surface area $\left(\mathrm{S}_{\mathrm{a}}\right)$ of $1.08 \mathrm{~m}^{2}$. $\mathrm{S}_{\mathrm{a}}$ was calculated as follows: As the volume of the anode graphite felt is $15 \mathrm{~cm} \times 7 \mathrm{~cm} \times 0.9 \mathrm{~cm}=94.5 \times$ $10^{-6} \mathrm{~m}^{3}<<$ the total volume of the anode $=0.0012 \mathrm{~m}^{3}(=30 \mathrm{~cm} \times$ $20 \mathrm{~cm} \times 2 \mathrm{~cm}$ ), the former can be considered negligible. Thus, $\mathrm{S}_{\mathrm{a}}=$ SSA of graphite granules $\times$ total volume of the anode, whereas SSA is the specific surface area. The SSA of graphite granules (considering the average diameter of the granules being $4 \mathrm{~mm}$ ) was calculated to be approximately $0.9 \times 10^{3} \mathrm{~m}^{2} \mathrm{~m}^{-3}\left(=6 \times(1-\theta) / \mathrm{d}_{50}\right.$, whereas $\theta$ is the porosity $(\sim 0.4)$ and $d_{50}$ is the $50 \%$ passing particle diameter $(4 \mathrm{~mm}))$, according to Srinivasan et al. (2016) [25]. With the volume of the anode being $0.0012 \mathrm{~m}^{3}, \mathrm{~S}_{\mathrm{a}}=0.9 \times 10^{3} \mathrm{~m}^{2} \mathrm{~m}^{-3} \times$ $0.0012 \mathrm{~m}^{3}=1.08 \mathrm{~m}^{2}$. Unless otherwise stated, all the values of average current densities and power densities reported in this study were the results of at least 3 repetitions.

Enrichment of Potentially Electroactive Microorganisms at the Sediment Anode of the System

The microbial source that was used for the enrichment of the SBES was a mixture of sediment mud samples collected from three different brackish-water shrimp ponds at Bang La lagoon (Ap Bac Ward, Do Son District, Vietnam) and the shrimp lagoon of Do Son Aquaculture Enterprise (Ngoc Xuyen Ward, Do Son District). $0.2 \mathrm{~kg}$ of this mixture was used for an even inoculation into the sediment of the test tank, resulting in a final 1-cm thick sediment above the anode granular layer. The same was done for the control tank. After inoculation, the tanks were fed at a rate of $0.051 \mathrm{~g} / \mathrm{d}$ per tank as described above, and the generation of electricity by the SBES integrated in the test tank was monitored. Once the electrical current was steadily generated (usually after 1-2 months of operation), indicating that the enrichment of electroactive bacteria was successful, the bacterial consortia in the sediment of both tanks would be analyzed.

\section{Sampling}

Each sediment sample (approximately $5 \mathrm{~g}$ ) was collected by spooning and mixing the mud at 5 points ( 4 at the corners and 1 at the center) of the sediment of each tank and stored at $-20^{\circ} \mathrm{C}$ for molecular analyses. For the test tank, the sediment sample contained the $5 \mathrm{~g}$ mud plus 5-6 granules of the anode.

The same procedure was applied for sediment samples used for
$\mathrm{COD}$, total nitrogen and $\mathrm{NH}_{4}{ }^{+}-\mathrm{N}$ analyses. However, in each experiment, at least 3 different samples were taken on different (and usually consecutive) days. Water samples (approximately $20 \mathrm{ml}$ each, in triplicate) (for $\mathrm{COD}$, total nitrogen, $\mathrm{NH}_{4}{ }^{+}-\mathrm{N}, \mathrm{NO}_{3}{ }^{-}$ and $\mathrm{NO}_{2}^{-}$analyses) were also collected at the middle level of the water body of each tank (about $5 \mathrm{~cm}$ vertically from the bottom) on the same days. All the water and sediment samples for those chemical analyses were taken after the enrichment period (after 1-2 months of operation), i.e. when the electricity generation was stable.

To measure the amount of sediment left after a year of operation, samples were collected from 3 random points of the sediment of each tank. At each point, the whole material from a sediment area of about $7 \mathrm{~cm}^{2}$ was taken by inserting the open mouth of a Falcon tube vertically from the sediment surface down to the bottom of the tank. The collected material was kept in the Falcon tube, before being withdrawn from the tank, by an additional manipulatable lid brought to the bottom to close the mouth of the tube.

\section{Molecular Methods for Analyzing the Bacterial Communities of the Sediments of the Systems}

To analyze the bacterial community in each sediment sample, total bacterial DNA in the sample was extracted and polymerase chain reaction (PCR) - denaturing gradient gel electrophoresis (DGGE) was carried out following previously reported procedures [26]. Briefly, samples were centrifuged $(4,000 \times g, 10 \mathrm{~min})$ before the pellets were used for DNA extraction, which was carried out using standard methods [27]. 16S rRNA gene fragments were amplified with the primers P63F (5'-CAGGCCTAACACATGCAA GTC-3') and P1378R (5'-CGGTGTGTACAAGGCCCGGGAACG$\left.3^{\prime}\right)$ [28]. The PCR products were subsequently used as the templates to amplify $(\sim 580 \mathrm{bp})$ fragments with the primers GM5FGC (5'-CCTACGGGAGGCAGCAGCGCCCGCCGCGCGCGG GGGGCGGGGCGGGGGCACGGGGG-3') and 907R (5'-CCGTCA ATTCCTTTRAGTTT-3') [29]. The final products were subjected to DGGE with a denaturing gradient ranging from 35 to $60 \%$ [29].

Bands of interest on DGGE gel were cut off from the gel and spliced into small pieces using a sterile razor. The small gel pieces were subsequently suspended in $50 \mu \mathrm{l}$ of deionized water for $24 \mathrm{~h}$ at $4^{\circ} \mathrm{C}$ to allow DNA to elute. The DNA eluted from each cut band was used as the template to amplify again the corresponding DNA fragment. The PCR products were purified with an ExoSAP-IT Kit (Affymetrix, USA) before being submitted to Integrated DNA Technologies (IDT, Singapore) for DNA sequencing.

The analysis of DNA sequences and homology searches were completed with standard DNA sequencing programs and the BLAST server of the National Center for Biotechnology Information (NCBI) using the BLAST algorithm [30].

\section{Chemical Analyses}

The COD of each sample was measured by the closed reflux colorimetric method, using chromate as the oxidant [31]. 
However, due to the high chloride concentration of the samples, they were pre-treated with $\mathrm{HgSO}_{4}$ [32]: every $10 \mathrm{ml}$ of a sample was mixed with $0.9 \mathrm{~g}$ of $\mathrm{HgSO}_{4}$, before being measured by the above-mentioned method.

Total nitrogen amount of each sample was measured by the Kjeldahl method while $\mathrm{NH}_{4}{ }^{+}$-nitrogen concentration was measured by the Nessler method [31]. $0.1 \mathrm{~N} \mathrm{Na}_{2} \mathrm{~S}_{2} \mathrm{O}_{3}$ solution was used to prevent the interference of chloride (one drop for every $0.3 \mathrm{mg} \mathrm{l}^{-1} \mathrm{Cl}^{-}$) (USEPA method 8038). The concentration of nitrate in each sample was measured using the spectrophotometric method ISO 7890-3: 1988; and that of nitrite was measured using the colorimetric method [31].

To determine the amount of sediment left after a year of operation, all the collected samples were dried to constant weight at $70^{\circ} \mathrm{C}$ and their weights measured.

\section{Data Analysis}

Three repetitions were done for all the experiments, unless otherwise stated. Data were analyzed by using basic statistical methods with tools in Microsoft Excel: differences in data were evaluated by $t$-Test analysis; errors among replicates were expressed in the form of standard deviations.

\section{Results}

\section{Generation of Electrical Currents during the Enrichment Process}

During the first eight days of the enrichment process, the electricity generation of the SBES in the test tank only increased slowly (Fig. 2). From the ninth day to the seventeenth day, the current increased significantly and then decreased slightly for four days. After about three weeks, the current became stable with an average level of $2.35 \mathrm{~mA}$, equivalent to an average current density of about $2.3 \mathrm{~mA} / \mathrm{m}^{2}$ (anode surface) and a power density of about $0.05 \mathrm{~mW} / \mathrm{m}^{2}$ (anode surface) (Fig. 2). These results suggested that electrochemically active bacteria seemed to have been enriched at the anode of the SBES.

\section{COD and Nitrogen Removal by the System}

After 1-2 months (after the enrichment period of the SBES), both the test tank and the control were fed with $0.051 \mathrm{~g}$ feed/d per tank for 2 weeks and later with $0.11 \mathrm{~g}$ feed/d per tank also for 2 weeks. Water and sediment samples were taken (daily) from the tanks and their COD, total nitrogen (TN), $\mathrm{NH}_{4}{ }^{+}-\mathrm{N}, \mathrm{NO}_{3}{ }^{-}$and $\mathrm{NO}_{2}{ }^{-}$concentrations were analyzed.

COD removal. The COD concentrations of the water samples from the test tank were lower than those from the control (Fig. 3). When the tanks were fed with $0.051 \mathrm{~g} / \mathrm{d}$ of feed per tank, the test tank could remove about $20 \%$ more
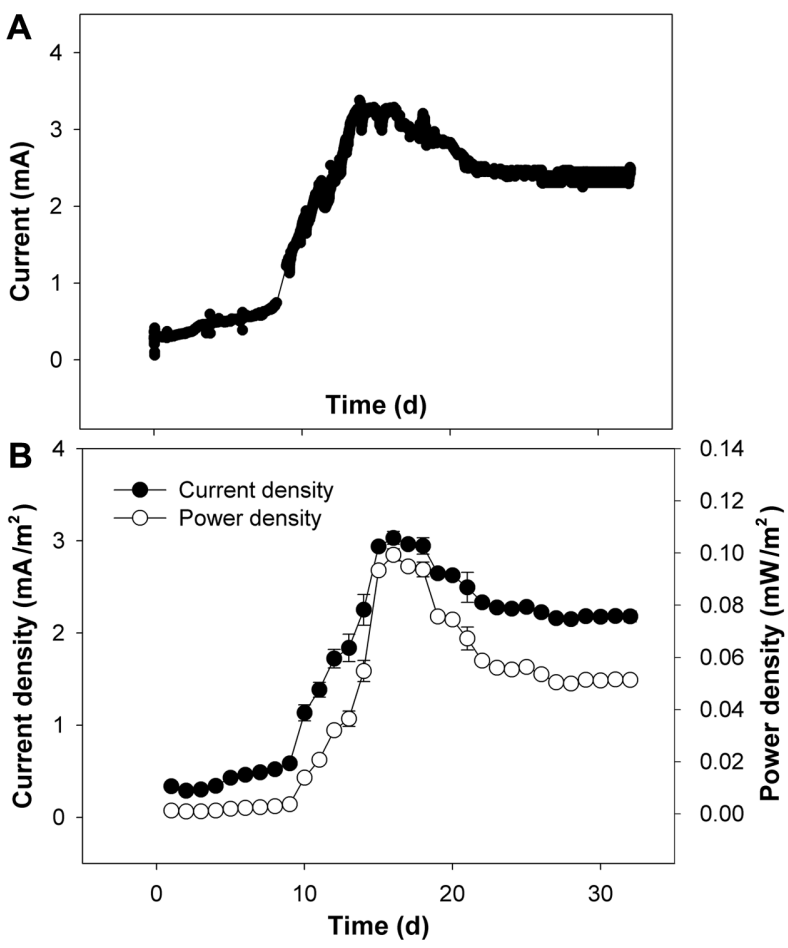

Fig. 2. The patterns of the real-time recorded electrical current (A) and the daily average current density and power density (B) generated by the SBES during the first 30 days (including the enrichment period) of the study.

COD content from the water than the control (Fig. 3). Interestingly, when the feed load was doubled, the test tank could even remove around 30\% more COD content from the water than the control (Fig. 3), although the remaining COD concentrations in both tanks were still high. These results demonstrate a more efficient COD removal when an SBES is installed in the pond model and suggest that the SBES effect is even more pronounced if the COD load in the system is high.

The COD concentrations of the sediment samples were subsequently measured. Interestingly, the COD concentration of the sediment of the test tank (with the SBES integrated) was not significantly different from that of the control (Fig. 3) $(p>0.05)$, no matter whether the tanks were fed with $0.051 \mathrm{~g} / \mathrm{d}$ per tank or with $0.11 \mathrm{~g} / \mathrm{d}$ per tank.

We further investigated the changes in the amount of sediment in both tanks. Surprisingly, after 1 year of operation, the amount of sediment in the test tank only reached $0.42 \pm 0.12 \mathrm{~g} / \mathrm{cm}^{2}$ of the sediment surface, while that in the control was $0.68 \pm 0.10 \mathrm{~g} / \mathrm{cm}^{2}$. Thus, the test tank could reduce about $40 \%$ the amount of the sediment after 1 year. Considering the fact that the sediment COD 

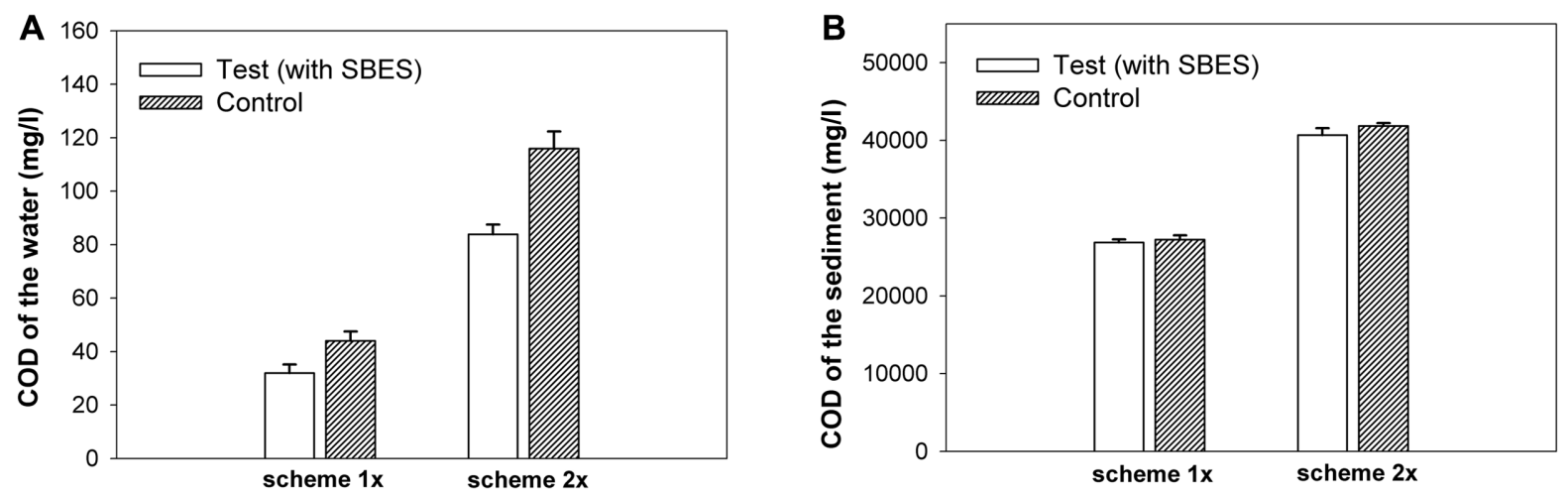

Fig. 3. Comparison of the COD levels of the water (A) and sediment samples (B) in the test tank with the SBES installed and in the control tank (without the SBES installed), in two feeding schemes.

Note: scheme 1x: the tanks were fed with $0.051 \mathrm{~g}$ feed/d per tank; scheme $2 \mathrm{x}$ : the tanks were fed with $0.11 \mathrm{~g}$ feed/d per tank. Detailed data can be found in Table S1.

concentrations in both tanks were the same, it can be deduced that the test tank could remove about $40 \%$ more sediment COD compared to the control.

Nitrogen removal by the system. The total Kjeldahl nitrogen (TKN) and $\mathrm{NH}_{4}^{+}-\mathrm{N}$ concentrations were not significantly different between the water of the test tank (with the SBES) and that of the control $(p>0.05)$, in both feeding schemes (Fig. 4). However, the TKN and $\mathrm{NH}_{4}{ }^{+} \mathrm{N}$ concentrations of the sediment of the test tank were significantly lower than those of the control $(p<0.05)$,
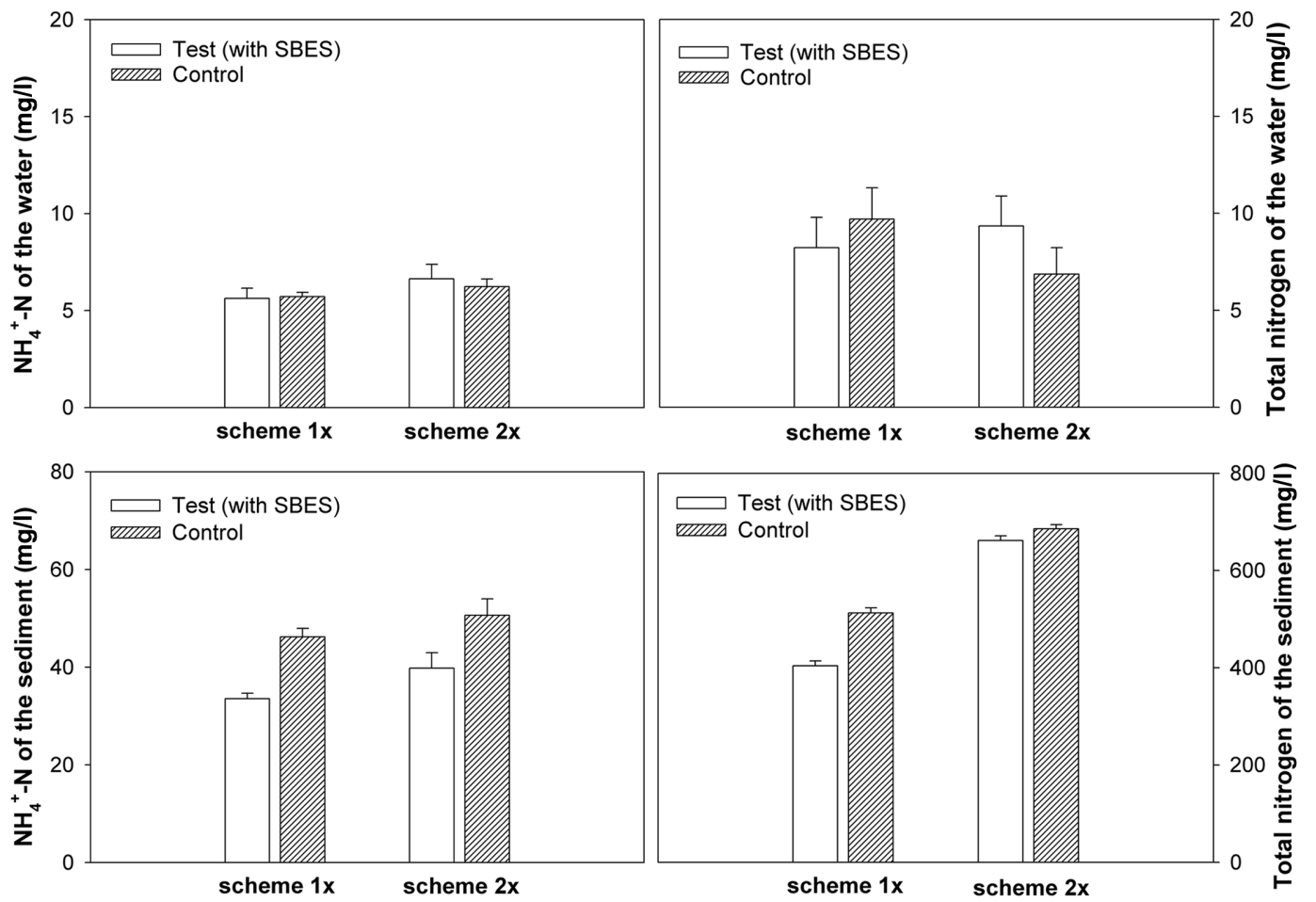

Fig. 4. Comparison of the $\mathrm{NH}_{4}{ }^{+}$-nitrogen content (left) and the total Kjeldahl nitrogen content (right) of the water (top) and sediment samples (bottom) in the test tank with the SBES installed and in the control tank (without the SBES installed), in two feeding schemes.

Note: scheme 1x: the tanks were fed with $0.051 \mathrm{~g}$ feed/d per tank; scheme $2 \mathrm{x}$ : the tanks were fed with $0.11 \mathrm{~g}$ feed/d per tank. 
particularly when the feeding rate was $0.051 \mathrm{~g} / \mathrm{d}$ per tank (scheme 1x) (Fig. 4). In this case, around 20\% more total nitrogen and $\mathrm{NH}_{4}{ }^{+}-\mathrm{N}$ were removed from the SBES sediment, compared to the control. When the feeding rate was doubled (scheme 2x), the SBES tank could still remove more $\mathrm{NH}_{4}{ }^{+} \mathrm{N}$ of the sediment than the control, although its total nitrogen removal was not better (Fig. 4).

Considering the higher reduction of sediment amount in the test tank than that in the control, it can be deduced that the removal of nitrogen (especially $\mathrm{NH}_{4}{ }^{+} \mathrm{N}$ ) from the sediment of the test tank is much more efficient than that in the control. Specifically, by taking into account the abovereported results that the test tank had $40 \%$ less sediment than the control after a year, and that the nitrogen content of the test tank sediment was 20\% less than that of the control tank sediment, we can deduce that the test tank can remove around $40 \%+20 \% * 60 \%=52 \%$ more sediment nitrogen than the control.

These results suggest a better removal of nitrogen and ammonia (in particular) in the model with an SBES installed.

Analyses were also done to measure the nitrate and nitrite concentrations in the samples, in order to investigate whether part of the nitrogen content in each tank could be converted to these potentially harmful products for aquaculture animals. Interestingly, the concentrations of nitrate and nitrite were at negligible levels in comparisons with those of total nitrogen and $\mathrm{NH}_{4}{ }^{+}-\mathrm{N}$ (Table S1).

\section{Bacterial Community at the Sediment Anode of the System}

The bacterial compositions of the inoculum and the sediments of the tanks (after six months of operation, i.e. when the performance of the system was stable) were analyzed and compared by denaturing gradient gel electrophoresis (DGGE) (Fig. 5). DGGE patterns clearly showed that the bacterial communities enriched in the sediments of the test tank (containing the SBES) and the control were significantly different from that of the inoculum. Indeed, dominant bands in the DGGE pattern of the inoculum (Fig. 5, bands I2, I3) indicate that the bacterial community of the inoculum was dominated mostly by the species that were not at all present in the experimentally enriched communities, such as Fictibacillus sp. and Brevibacillus sp. This implies changes in the bacterial composition of the inoculum, which is a mixture of many microbial sources, to adapt to the experimental conditions, particularly in the case of the SBES system. The control



Fig. 5. DGGE analysis to compare the bacterial communities of the inoculum (Ino), the sediment of the test tank with the SBES installed (Test), and the sediment of the control tank (without the SBES installed) (Ctrl).

The note on each arrow indicates the genus or the species, $16 \mathrm{~S}$ rDNA sequence of which has the highest similarity to the sequence of the DNA fragment represented by the corresponding band on the gel (based on BLAST analysis, Table S2). Abbreviations: Brevu = Brevundimonas sp., Brevi = Brevibacillus chosinensis, Desub = Desulfobacula toluolica, Desuf $=$ Desulfatitalea tepidiphila, Fictib = Fictibacillus phosphorivorans, Methy $=$ Methylophilus rhizosphaerae, Thiot $=$ Thiothrix eikelboomii, Unkn = unknown bacterium. The note next to each arrow is the assigned number of the corresponding band. The DGGE was repeated 3 times with 3 replicates of each sample. Since the results of these repetitions were absolutely similar, only typical patterns were shown here.

tank sediment community, however, still seems to share some common species with the inoculum (demonstrated by some common DGGE bands, including band C1 and some nearby bands). This indicates less significant changes in the bacterial composition from the community of the inoculum to the control tank sediment community than to the test tank sediment community. However, some distinct bands $(C 2, C 3)$ reflect the presence of some distinct species (Desulfobacula toluolica and an unknown species) in the 
community of the control tank. Interestingly, the test tank sediment community was dominated by distinct species such as Methylophilus rhizosphaerae, Desulfatitalea tepidiphila and Thiothrix eikelboomii, which are quite uncommon in surrounding environments in general and in bioelectrochemical systems in particular. Thus, the test tank community appeared to be highly different from the other communities, although it seemed to still share a common dominant species, possibly a Brevundimonas sp., with them (Fig. 5, band T2).

\section{Discussion}

\section{The Establishment of a Functional SBES Integrated in a Brackish Aquaculture Pond Model}

As stated above, in this study, we have successfully designed and constructed, at laboratory scale, a brackish aquaculture pond model with an SBES integrated into it and also successfully enriched electrochemically active bacteria at the SBES anode. The results of our study strongly suggest that such an SBES can fully function under brackish conditions. This is demonstrated by the generation of electricity (Fig. 2) and the presence of halophilic bacteria in the community of the SBES sediment. In fact, sediment BES or sediment microbial fuel cell (MFC) or benthic BES/MFC are not new. The idea of installing an anodic electrode into the sediment or seafloor to harvest electrical energy was presented since the 2000s [8, 10]. These systems could generate electricity upon oxidizing organic matter in the water and the sediment. In another study, the SMFC was employed to supply power for remote sensors to monitor the water quality of the ocean [33]. More recently, numerous studies have explored the applicability of SMFCs to remove organic contents (including recalcitrant hydrocarbons and/or nitrate) in marine waters or sediments while simultaneously recovering energy [3436]. Nonetheless, no study has inspected SBESs in the aspect of using them as a technology to treat brackish water or wastewater in brackish aquaculture systems. A recent striking research on the use of SMFC to remediate aquaculture ponds has been reported by Sajana et al. [1] but the investigated SBES was only applied for freshwater systems. In that SBES, graphite plates were used as the electrodes and their limited surface area might be the reason for the low power output of the system. In this study, graphite granules were used as the main components of the anode so as to increase the contact area and thereby stimulating more bacterial growth as well as enhancing the waste-to-energy conversion.

\section{Bacteria Enriched in the Anode Sediment of the SBES Integrated in a Brackish Aquaculture Pond Model}

As mentioned, in the only study reported thus far on the application of SBES in aquaculture systems by Sajana et al., no investigation of the involved microorganisms was carried out and thus no information about them has been known [1]. In other studies on benthic or sediment electrochemical systems, investigations on the bacterial communities of the sediments revealed the presence of typically electrochemically active bacteria, such as Geobacter spp. [10, 37]. However, in our study, no Geobacter was detected. Halophilic bacteria such as Pseudomonas xanthomarina and Vibrio sp. could be cultured from the bacterial community of the SBES [38] anode but not found dominant (as revealed by DGGE results). Instead, Methylophilus rhizosphaerae, Desulfatitalea tepidiphila and Thiothrix eikelboomii, which have not been reported in any BES, seem to dominate the community of the test tank sediment (but not that of the control tank sediment) (Fig. 5). This fact suggests that the bacteria that play the central role in the electrochemical activity of the whole community might be novel ones. Methylophilus rhizosphaerae was found common in the rhizosphere and reported to use single carbon compounds and can not live at concentrations of $\mathrm{NaCl}$ higher than $2 \%$, meaning that it can still survive in brackish systems though [39]. Thus this species probably uses post-methanogenesis products (e.g. methanol once the anaerobically produced methane is oxidized by methanotrophs upon contacting more oxygen after escaping from the sediment). However, it is questioned whether this bacterium can transfer electrons to the electrode or just simply produces substrates for the electroactive bacteria. A similar question is for Thiothrix eikelboomii, as this species is known to be present in activated sludge and to have a complex heterotrophic lifestyle metabolizing various kinds of organic substrates [40] but not yet reported to be electrochemically active. It was reported that both Thiothrix eikelboomii and Methylophilus rhizosphaerae can reduce nitrate $[39,40]$ and Desulfatitalea tepidiphila is a sulfatereducer [41]. The presence of Desulfatitalea tepidiphila in the community of the SBES sediment is reasonable as it was found dominant in brackish environments, such as tidal flat sediments, and capable of using various electron donors [41]. However, like the other two, this species has not been reported to be electrochemically active. On the other hand, another sulfate-reducer, Desulfobacula toluolica, was also found dominant in the community of the control tank. In fact, sulfate-reducers can be found present in any sediment or anoxic environment [42]. Therefore, it is more 
uncertain whether those anaerobic respirers can transfer electrons to the electrode or they merely are part of natural anaerobic consortia carrying out anaerobic processes that may actually compete with bioelectrochemical processes.

In brief, there are two possible hypotheses about the role of the bacteria dominating the sediment community of the SBES: The first one is that they are electroactive, utilizing organic materials as their electron donors and reducing the anodic electrode, just like what they do to their familiar non-oxygen electron acceptors. The second is that they only support or benefit from electrochemically active bacteria, which may only account for less than $20 \%$ of the community mass (and may be underpresented by DGGE bands) but take over $80 \%$ of the job, according to ParetoLorenz law [43]. The second seems less convincing as the bacteria that play the role of supporting members may be already present: the Brevundimonas species. These bacteria are present in all the communities of the inoculum, the control tank and the SBES-containing tank (as demonstrated by the DGGE result). Brevundimonas species are Pseudomonaslike bacteria present in all kinds of environments and have a very versatile metabolism enabling them to utilize diverse substrates [44]. Thus, it is highly possible that the presence of Brevundimonas species is essential, to break down complex organic materials for other bacteria (the anaerobic degraders in the control or the electrochemically active degraders in the SBES) to metabolize. The DGGE result (Fig. 5) also shows that the Brevundimonas species are more dominant in the communities of the inoculum and particularly of the control than in that of the test tank. Moreover, Methylophilus rhizosphaerae, Desulfatitalea tepidiphila and Thiothrix eikelboomii were typically dominant in the electricity-generating SBES community while not at all found in the others. Therefore, with Brevundimonas species probably serving as supporting partners, the three dominant species of the SBES are more likely to be involved in the electrochemical processes in the system. In other words, our first hypothesis is more strongly supported.

\section{The Application Potential of Using the Established Model for the Treatment of Water and Sediment in Brackish Aquaculture Ponds}

The results reported above suggest that an SBES can be integrated into a brackish aquaculture system to remove COD and nitrogen content in situ.

Regarding COD removal, as mentioned above, our SBES could remove $20-30 \%$ more COD of the pond water, compared to natural degradation (the control). Sajana et al. [1] reported a 2-fold faster COD removal rate offered by an
SBES compared to natural degradation, in a fresh water system. This implies 50\% more COD removal due to the SBES in the fresh water system. Our hypothesis for such difference in COD removal between the two SBESs is that probably in a brackish environment as in our system, the activity of electrochemically active bacteria can not be comparable to that in a fresh water environment, due to harsher conditions. Nonetheless, it should be noted that our system was fed in a scheme mimicking that in reality (i.e. daily feeding, as if shrimps were being reared in the tanks), while the system of Sajana et al. was only fed once at the beginning of each batch that might last (9-22 days) until COD concentration dropped down to the acceptable level. Thus the feed load into our system, being much closer to practical conditions, is much more intensive than that in Sajana et al.'s system; implying that the COD removal enhancement by the SBES in our system is practical and meaningful. Furthermore, another positive point is that under such a consecutive daily feeding scheme as in practice, the COD concentration of the water in the tank containing the SBES could be still reduced to around $30 \mathrm{mg} / \mathrm{l}$, i.e. at a level considered acceptable for aquaculture pond water [1], while that of the control was still above the acceptable level. Interestingly, our pond model SBES could reduce about $40 \%$ more the amount of sediment, i.e. $40 \%$ more sediment COD, compared to natural degradation (most probably solely by anaerobic digestion). Another possibility not to be excluded is that it might be the very enhancement in water COD removal by the SBES that might lead to faster solubilization and thus reduced amount of sediment in the test tank. Even if that is the case, the ultimate consequence is still more COD sediment reduction by SBES. The results demonstrate a promising potential of the SBES in removing COD contents of brackish aquaculture ponds.

It may be noted that the COD concentrations of the sediments in both the test tank and the control tank were at the same level. This result is actually reasonable because the sediment amount may be changed due to digestion or (bio)electrochemical oxidation, but the sediment COD content including bacterial biomass and undissolved organic feed as well as their densities should remain constant in both tanks when under the same ambient conditions.

With respect to nitrogen removal, the results imply that the SBES does not seem to boost up the removal of nitrogen content of the pond water. The total nitrogen level of the test tank water was even higher than that of the control when the feeding rate was doubled (scheme 2x). Possibly, 
with a high organic strength in the water, electrochemically active bacteria in the SBES perform worse in removing nitrogen while this may not be a problem to natural anaerobic degradation. Indeed, anaerobic degradation is believed to have advantages over bioelectrochemical degradation for high organic strength (waste)water [45, 46]. In our SBES-containing tank, the total nitrogen level and $\mathrm{NH}_{4}{ }^{+}-\mathrm{N}$ level of the water could be reduced down to around $6 \mathrm{mg} / 1$ and $8 \mathrm{mg} / 1$, respectively. In Sajana et al.'s system, $\mathrm{NH}_{4}{ }^{+}-\mathrm{N}$ could be reduced down to $0.36 \mathrm{mg} / 1$ after 9 days [1] but as mentioned above, their system was fed only once per batch, not as intensively as in reality as in our system. Moreover, Sajana et al. [1] did not present any data about nitrogen removal by their control system, thus it is difficult to judge whether water nitrogen removal by their SBES was more efficient than natural degradation or not.

Although the performance of the SBES in terms of removing nitrogen from the water was not impressive, its capability of reducing about $50 \%$ of the nitrogen content (including ammonium-nitrogen) of the sediment is very encouraging. Sajana et al. [1] did not investigate the reduction of sediment nitrogen but a reduction of oxidizable organic matter amount from $2.1 \%$ to around $0.6 \%$ of sediment was also observed [1].

The observation that little nitrite and nitrate were formed in the tank containing the SBES is interesting. Sajana et al. [1] reported significant increases in nitrite and nitrate concentrations in their systems, indicating that nitrogen was not removed completely but partially trapped in their pond in the forms of nitrate and nitrite. In brackish systems like in this study, the halophilic sediment bacteria probably perform more efficient denitrification, leading to a complete nitrogen removal. Indeed, there has been experimental evidence that high salinity conditions (in wastewater treatment plants) led to a higher denitrification performance than that under low salinity conditions [47]. The reason is believed to be the dominance of halophilic denitrifiers in the bacterial community under high salinity conditions [47], while these conditions on the other hand can reduce the diversity of the community [48]. Probably, what happens to denitrification in the brackish systems (in our study) is similar, explaining for a more efficient nitrogen removal compared to that in freshwater systems. That hypothesis is also supported by the fact that the dominant species of the SBES bacterial community (Methylophilus rhizosphaerae and Thiothrix eikelboomii) can reduce nitrate. Ultimately, we should not exclude the possibility that the complete ammonia oxidizers (coammox) may play a key role in removing nitrogen in the system [49,
50], although their DNA traces were not detected in our DGGE analysis. Indeed, there has been no evidence that coammox could transfer electrons to an anode but it is thermodynamically possible that they can do it.

The reported performance of our SBES poses a great potential of using this system for in situ reclamation of water and sediment in brackish aquaculture systems. Our results suggested that, in reality, a similar SBES installed into a brackish aquaculture pond can be functional. In addition to the removal of water COD, the SBES was shown to even function efficiently in removing COD and nitrogen contents of the brackish aquaculture sediment, particularly through reducing the sediment amount. Indeed, the use of bioelectrochemical systems such as microbial fuel cells as an efficient solution for sludge reduction in wastewater treatment has been proven [5153] but their application to reduce sediment in aquaculture ponds has not been reported. Partial conversion of the energy in organic matter of sludge to electricity are believed to reduce the cell yield (or biomass production), leading to sludge reduction in wastewater treatment [5153]. It is highly possible that the mechanism of in situ sediment reduction by the SBES in a pond model is similar. Sediment issues are actually of more concern as organic and nitrogen contents in the sediment might trigger the spread of pathogens in aquaculture ponds [54]. Moreover, a large amount of sediment also causes the rise of COD and nitrogen contents in the pond water, a major cause of eutrophication, the consequence of which can lead to massive death of aquatic animals [55]. Thus, the reported capability of the SBES in reducing the brackish pond sediment is of great importance.

With the in situ bioremediation potential mentioned above, the SBES can become a very competitive technology also due to its low cost. The absence of the expensive membrane significantly reduces the cost to fabricate an SBES. The major cost will be graphite granules. With many manufacturers supplying this material, the cost of graphite granules is becoming relatively low now (at about 0.7 USD per kg, according to https: / / www.alibaba.com). Moreover, another great factor making the SBES a cost-efficient technology is its long lifetime: it can be used and reused for years. In addition, the sediment reduction by the SBES, as mentioned above, can definitely help save the cost for sediment treatment or removal. More importantly, the in situ treatment capability of the SBES enables a significant reduction in energy used, compared to other competing technologies. As also discussed by Sajana et al. [1], compared to other aeration-based technologies for the 
bioremediation of aquaculture systems, the use of SBES (or SMFC) can help save significant amounts of energy used for aeration (up to $3.65 \mathrm{~kW} / \mathrm{d}$ ). Other methods involving water exchange also require power for pumping water (up to $820 \mathrm{~kW} /$ ha pond area every 6 months) [1] whereas the use of an SBES can eliminate this practice. Those issues can become more practically serious for brackish aquaculture systems, where equipment faces corrosion problems and water salinity should be maintained stable. As for our SBES, most of the key components are graphite-based and thus corrosion-free, though the use of metallic current collectors may be under consideration as they were reported to improve the performance of other BESs [56]. Therefore, apparently the use of an SBES is a prospective efficient approach for the treatment of water and sediment in brackish aquaculture systems.

It should be noted that this research was conducted with the assumption that the effect of excreta from aquaculture animals could be neglected. Thus all the obtained data and observed phenomena are based upon this assumption. It is possible that the performance of the SBES as well as the microbial community in its sediment can be partially affected by the excreta although the remaining feeds may have a major effect. Therefore, this issue should be considered in later scale-up studies.

In summary, in this study, we have successfully developed a sediment bioelectrochemical system (SBES) integrated into a brackish aquaculture tank model. Overall, the results showed that the SBES functioned properly, producing electricity with an average current density of $2.3 \mathrm{~mA} / \mathrm{m}^{2}$ anode surface and an average power density of $0.05 \mathrm{~mW} / \mathrm{m}^{2}$ anode surface. Such a functional SBES could enhance the removal of the water COD (by 20-30\%) and particularly the removal of COD and nitrogen of the sediment (by approximately $40 \%$ and $52 \%$, respectively) in the model aquaculture system. Thus, this study demonstrated a promising application potential SBES for in situ reclamation of water and sediment in brackish aquaculture systems. Furthermore, distinct bacteria not yet found in reported bioelectrochemical systems, including a methylotroph and some untypical anaerobic respirers, are believed to play the key role in the performance of the SBES and require further investigation.

\section{Acknowledgments}

This research is funded by Vietnam National Foundation for Science and Technology Development (NAFOSTED) under grant number 106-NN.04-2015.23. The authors would like to deeply thank Prof. Te Quang Bui from Research Institute for Aquaculture No. 1, Bac Ninh, Vietnam for his valuable comments and information sharing. The authors also thank Ms. Chien and the staff at Center for Experimental Biology, National Center for Technological Progress (NACENTECH), Vietnam for their kind help during the completion of the study.

\section{Conflict of Interest}

The authors have no financial conflicts of interest to declare.

\section{References}

1. Sajana TK, Ghangrekar MM, Mitra A. 2013. Application of sediment microbial fuel cell for in situ reclamation of aquaculture pond water quality. Aquac. Eng. 57: 101-107.

2. Official website of the Directorate of Fisheries - Vietnam Ministry of Agriculture and Rural Development: https:// tongcucthuysan.gov.vn.

3. Boyd CE. 1998. Pond water aeration systems. Aquac. Eng. 18: $9-40$.

4. van Rijn J. 1996. The potential for integrated biological treatment systems in recirculating fish culture-a review. Aquac. 139: 181-201.

5. Lin Y-F, Jing S-R, Lee D-Y, Wang T-W. 2002. Nutrient removal from aquaculture wastewater using a constructed wetlands system. Aquac. 209: 169-184.

6. Zou S, Guan L, Taylor DP, Kuhn D, He Z. 2018. Nitrogen removal from water of recirculating aquaculture system by a microbial fuel cell. Aquac. 497: 74-81.

7. Marx Sander E, Virdis B, Freguia S. 2018. Bioelectrochemical denitrification for the treatment of saltwater recirculating aquaculture streams. ACS Omega 3: 4252-4261.

8. Reimers CE, Tender LM, Fertig S, Wang W. 2001. Harvesting energy from the marine sediment-water interface. Environ. Sci. Technol. 35: 192-195.

9. Jang JK, Pham TH, Chang IS, Kang KH, Moon H, Cho KS, et al. 2004. Construction and operation of a novel mediatorand membrane-less microbial fuel cell. Process Biochem. 39: 1007-1012.

10. Bond DR, Holmes DE, Tender LM, Lovley DR. 2002. Electrode-reducing microorganisms that harvest energy from marine sediments. Science 295: 483-485.

11. Hong S, Choi Y, Chung T, Song J, Kim H. 2009. Assessment of sediment remediation potential using microbial fuel cell technology. World Acad. Sci. Eng. Technol. 54: 683-689.

12. Morris JM, Jin S. 2012. Enhanced biodegradation of hydrocarbon-contaminated sediments using microbial fuel cells. J. Hazard. Mater. 213: 474-477. 
13. Sherafatmand M, Ng HY. 2015. Using sediment microbial fuel cells (SMFCs) for bioremediation of polycyclic aromatic hydrocarbons (PAHs). Bioresour. Technol. 195: 122-130.

14. An J, Kim B, Nam J, Ng HY, Chang IS. 2013. Comparison in performance of sediment microbial fuel cells according to depth of embedded anode. Bioresour. Technol. 127: 138-142.

15. Ewing T, Ha PT, Babauta JT, Tang NT, Heo D, Beyenal H. 2014. Scale-up of sediment microbial fuel cells. J. Power Sources 272: 311-319.

16. De Schamphelaire L, Rabaey K, Boeckx P, Boon N, Verstraete W. 2008. Outlook for benefits of sediment microbial fuel cells with two bio-electrodes. Microbial Biotechnol. 1: 446-462.

17. Donovan C, Dewan A, Heo D, Beyenal H. 2008. Batteryless, wireless sensor powered by a sediment microbial fuel cell. Environ. Sci. Technol. 42: 8591-8596.

18. Scott K, Cotlarciuc I, Head I, Katuri KP, Hall D, Lakeman $\mathrm{JB}$, et al. 2008. Fuel cell power generation from marine sediments: Investigation of cathode materials. J. Chem. Technol. Biotechnol. 83: 1244-1254.

19. Tender LM, Reimers CE, Stecher HA, Holmes DE, Bond DR, Lowy DA, et al. 2002. Harnessing microbially generated power on the seafloor. Nat. Biotechnol. 20: 821-825.

20. Bui TQ. 2010. Standard protocols of rearing shrimps following good aquaculture practice (GAP) (in Vietnamese), pp. 1-17. Ed. Research Institute of Aquaculture No. 1, Bac Ninh, Vietnam.

21. Tacon AGJ, Phillips MJ, Barg UC. 1995. Aquaculture feeds and the environment: The asian experience. Water Sci. Technol. 31: 41-59.

22. Hasan M. 2000. Presented at the Aquaculture in the third millennium. Technical proceedings of the conference on aquaculture in the third millennium, Bangkok, Thailand.

23. Aelterman P, Rabaey K, Pham HT, Boon N, Verstraete W. 2006. Continuous electricity generation at high voltages and currents using stacked microbial fuel cells. Environ. Sci. Technol. 40: 3388-3394.

24. Logan BE, Hamelers B, Rozendal R, Schrorder U, Keller J, Freguia S, et al. 2006. Microbial fuel cells: Methodology and technology. Environ. Sci. Technol. 40: 5181-5192.

25. Srinivasan V, Weinrich J, Butler C. 2016. Nitrite accumulation in a denitrifying biocathode microbial fuel cell. Environ. Sci: Water Res. Technol. 2: 344-352.

26. Nguyen TT, Luong TTT, Tran PHN, Bui HTV, Nguyen HQ, Dinh HT, et al. 2015. A lithotrophic microbial fuel cell operated with pseudomonads-dominated iron-oxidizing bacteria enriched at the anode. Microbial Biotechnol. 8: 579589.

27. Boon N, Goris J, De Vos P, Verstraete W, Top EM. 2000. Bioaugmentation of activated sludge by an indigenous 3chloroaniline-degrading Comamonas testosteroni strain, I2gfp. Appl. Environ. Microbiol. 66: 2906-2913.

28. Muyzer G, de Waal EC, Uitterlinden A. 1993. Profiling of complex microbial populations using denaturing gradient gel electrophoresis analysis of polymerase chain reactionamplified genes coding for $16 \mathrm{~S}$ rRNA. Appl. Environ. Microbiol. 59: 695-700.

29. Muyzer G, Teske A, Wirsen CO, Jannasch HW. 1995. Phylogenetic relationships of Thiomicrospira species and their identification in deep-sea hydrothermal vent samples by denaturing gradient gel electrophoresis of $16 \mathrm{~S}$ rDNA fragments. Arch. Microbiol. 164: 165-172.

30. Altschul SF, Gish W, Miller W, Myers EW, Lipman DJ. 1990. Basic local alignment search tool. J. Mol. Biol. 215: 403-410.

31. Greenberg A, Clesceri LS, Eaton AD. 1998. Standard Methods for the Examination of Water and Wastewater, 20th Edn, pp. 5-16 - 5-19. Ed. American Public Health Association, Washington DC

32. Vyrides I, Stuckey D. 2009. A modified method for the determination of chemical oxygen demand (COD) for samples with high salinity and low organics. Bioresour. Technol. 100: 979-982.

33. Shantaram A, Beyenal H, Raajan R, Veluchamy A, Lewandowski Z. 2005. Wireless sensors powered by microbial fuel cells. Environ. Sci. Technol. 39: 5037-5042.

34. Zhang Y, Angelidaki I. 2012. Bioelectrode-based approach for enhancing nitrate and nitrite removal and electricity generation from eutrophic lakes. Water Res. 46: 6445-6453.

35. Wang A, Cheng H, Ren N, Cui D, Lin N, Wu W. 2012 Sediment microbial fuel cell with floating biocathode for organic removal and energy recovery. Front. Environ. Sci. Eng. 6: 569-574.

36. Cruz Viggi C, Presta E, Bellagamba M, Kaciulis S, Balijepalli S, Zanaroli G, et al. 2015. The "Oil-Spill Snorkel": an innovative bioelectrochemical approach to accelerate hydrocarbons biodegradation in marine sediments. Front. Microbiol. 6: 881.

37. Lovley DR. 2006. Bug juice: harvesting electricity with microorganisms. Nat. Rev. Microbiol. 4: 497-508.

38. Hien TT, Linh VT, Hai PT. 2016. Bacteria isolated from the sediment of a bioelectrochemical system installed in a simulated aquaculture pond operated with brackish water. VNU J. Nat. Sci. Technol. 32: 233-241.

39. Madhaiyan M, Poonguzhali S, Kwon S-W, Sa T-M. 2009. Methylophilus rhizosphaerae sp. nov., a restricted facultative methylotroph isolated from rice rhizosphere soil. Int. J. Syst. Evol. Microbiol. 59: 2904-2908.

40. Howarth R, Unz RF, Seviour EM, Seviour RJ, Blackall LL, Pickup RW, et al. 1999. Phylogenetic relationships of filamentous sulfur bacteria (Thiothrix spp. and Eikelboom type $021 \mathrm{~N}$ bacteria) isolated from wastewatertreatment plants and description of Thiothrix eikelboomii sp. nov., Thiothrix unzii sp. nov., Thiothrix fructosivorans sp. nov. and Thiothrix defluvii sp. nov. Int. J. Syst. Evol. Microbiol. 49: 1817-1827.

41. Higashioka Y, Kojima H, Watanabe M, Fukui M. 2013. Desulfatitalea tepidiphila gen. nov., sp. nov., a sulfate- 
reducing bacterium isolated from tidal flat sediment. Int. J. Syst. Evol. Microbiol. 63: 761-765.

42. Widdel F, Bak F. 1992. Gram-Negative Mesophilic SulfateReducing Bacteria, pp. 3352-3378. In Balows A, Trüper HG, Dworkin M, Harder W, Schleifer K-H (eds.), The Prokaryotes: A Handbook on the Biology of Bacteria: Ecophysiology, Isolation, Identification, Applications, Ed. Springer New York, New York, NY

43. Verstraete W, Wittebolle L, Heylen K, Vanparys B, de Vos P, van de Wiele $\mathrm{T}$, et al. 2007. Microbial resource management: the road to go for environmental biotechnology. Eng. Life Sci. 7: 117-126.

44. Ryan MP, Pembroke JT. 2018. Brevundimonas spp: emerging global opportunistic pathogens. Virulence 9: 480-493.

45. Pham TH, Rabaey K, Aelterman P, Clauwaert P, De Schamphelaire L, Boon $\mathrm{N}$, et al. 2006. Microbial fuel cells in relation to conventional anaerobic digestion technology. Eng. Life Sci. 6: 285-292.

46. Puig S, Serra M, Coma M, Balaguer M, Colprim J. 2011. Simultaneous domestic wastewater treatment and renewable energy production using microbial fuel cells (MFCs). Water Sci. Technol. 64: 904-909

47. Yoshie S, Makino H, Hirosawa H, Shirotani K, Tsuneda S, Hirata A. 2006. Molecular analysis of halophilic bacterial community for high-rate denitrification of saline industrial wastewater. Appl. Environ. Microbiol. 72: 182-189.

48. Yoshie S, Noda N, Tsuneda S, Hirata A, Inamori Y. 2004. Salinity decreases nitrite reductase gene diversity in denitrifying bacteria of wastewater treatment systems. Appl. Environ. Microbiol. 70: 3152-3157.

49. Kits KD, Sedlacek CJ, Lebedeva EV, Han P, Bulaev A, Pjevac $\mathrm{P}$, et al. 2017. Kinetic analysis of a complete nitrifier reveals an oligotrophic lifestyle. Nature 549: 269-272.

50. Koch H, van Kessel MA, Lücker S. 2019. Complete nitrification: insights into the ecophysiology of comammox Nitrospira. Appl Environ. Microbiol. 103: 177-189.

51. Gajaraj S, Hu Z. 2014. Integration of microbial fuel cell techniques into activated sludge wastewater treatment processes to improve nitrogen removal and reduce sludge production. Chemosphere 117: 151-157.

52. Xiao B, Luo M, Wang X, Li Z, hen H, Liu J, et al. 2017. Electricity production and sludge reduction by integrating microbial fuel cells in anoxic-oxic process. Waste Manag. 69: 346-352.

53. Borea L, Puig S, Monclús H, Naddeo V, Colprim J, Belgiorno V. 2017. Microbial fuel cell technology as a downstream process of a membrane bioreactor for sludge reduction. Chem. Eng. J. 326: 222-230.

54. Boyd CE, Schmittou HR. 1999. Achievement of sustainable aquaculture through environmental management. Aquac. Economics Manag. 3: 59-69.

55. Camargo JA, Alonso Á. 2006. Ecological and toxicological effects of inorganic nitrogen pollution in aquatic ecosystems: a global assessment. Environ. Int. 32: 831-849.

56. Wei J, Liang P, Huang X. 2011. Recent progress in electrodes for microbial fuel cells. Bioresour. Technol. 102: 9335-9344. 